\title{
Correspondence
}

\section{Kawasaki disease}

Sir,

I read with interest the letter of Morgan and Lynch (Archives, 1978, 53, 916), and should like to report 2 more white children in the UK-one Welsh and one English.

A 6-year-old boy from Anglesey was admitted in June 1978; 2 weeks previously he had developed fever and a blotchy red rash over the face with red macules on the trunk. He was seen by his doctor, diagnosed as having tonsillitis and scarlet fever, and given a 5-day course of ampicillin. His condition did not improve. On the 12th and 13th days of his illness (two days before admission) he developed peripheral limb pain, particularly around fingers, wrists, ankles, and toes. He was febrile, $38 \cdot 6^{\circ} \mathrm{C}$. There was bilateral cervical lymphadenopathy. The throat was inflamed. There was a grade-1 systolic murmur. Swelling of the fingers, hands, and wrists was noted. At this stage no firm diagnosis was made, but 3 days later prominent tongue papillae, oedema proceeding to skin peeling of the hands and feet, and a high ESR $(100 \mathrm{~mm}$ in the 1st hour) were noted, and the diagnosis of mucocutaneous lymph node syndrome (MLNS) was made. $\mathrm{Hb}$ was $10.6 \mathrm{~g} / \mathrm{dl}$. Other investigations gave normal results: white blood count, urine analysis and culture, ASO, throat swab, chest $x$-ray, Paul Bunnell test, blood culture, and ECG.

After 18 days' illness his temperature remitted. The skin continued flaking from the periphery for another 2 weeks, but otherwise he was well, and has remained so for the subsequent 5 months.

A 31-year-old girl from Merseyside on holiday in Wales presented with a 4-day history of fever for which a doctor had prescribed ampicillin. She had experienced a sore throat, a slight cough, and a few loose stools. The day before admission she had developed an erythematous rash with peeling on the face, trunk, and nappy area.

On examination she had a fever of $39 \cdot 5^{\circ} \mathrm{C}$. There was cervical lymphadenopathy, and an erythematous rash on the face, upper trunk, and nappy areas, with peeling around the nappy area. The tongue papillae were unusually and markedly prominent. The throat and ear drums were injected. There was no heart murmur. $\mathbf{H b}$ was $10.8 \mathrm{~g} / \mathrm{dl}$, ESR $106 \mathrm{~mm}$ in the $1 \mathrm{st}$ hour, urine trace albumin, nil sugar, microscopy and culture negative, CSF normal, throat swab negative, ASO 605 units, blood culture negative, plasma Na $128 \mathrm{mmol} / 1, \mathrm{~K} 4.8 \mathrm{mmol} / 1$, $\mathrm{Cl} 98 \mathrm{mmol} / 1$, plasma urea $20 \mathrm{mg} / 100 \mathrm{ml}(3.3 \mathrm{mmol} / \mathrm{l})$, ECG normal, chest $x$-ray normal, C3 complement $1 \cdot 16 \mathrm{~g} / 1$ (raised).

Initially the diagnosis was thought to lie between toxic epidermolysis, due to a staphylococcal toxin, and MLNS. Treatment was started with IV fucidin to no effect, the child remaining febrile and ill. On the 8th day of illness, oedema of the extremities developed and peripheral joint arthralgia. On the 9th day the child was transferred to Alder Hey Children's Hospital, Liverpool, under the care of Professor Harris to be closer to her home. The oedema and arthralgia of the periphery subsided quickly, but the skin of the periphery continued to peel for 2 or 3 weeks. She subsequently recovered completely (4 months later).

R. H. DAvies

St David's Hospital,

Bangor,

Gwynedd LL57 4SL

\section{Acquired toxoplasmosis and acute hemisyndrome in childhood}

\section{Sir,}

In an article (Archives, 1978, 53, 414) McNicholl and Flynn reported on 9 cases of acquired toxoplasmosis in childhood, 2 of whom contracted an acute hemisyndrome with persisting sequelae. We observed a similar case in a 5-year-old boy who gradually developed hemiplegia over 24 hours (9-10 December 1977). The boy had been treated with penicillin for an otitis media during the preceeding week. On admission he had a complete leftsided hemiparesis, but had neither lymphoglandular enlargement nor chorioretinitis. An acute right carotid angiography, isotope, and computerised axial tomography (CAT) scans were negative. A repeat CAT scan 6 months later was still normal. CSF findings were inconclusive. Improvement was initially rapid but subtotal. Currently, one year later, only a slight left-sided dysfunction and spasticity remains.

The patient is a farmer's boy and had been playing with his cat. Toxoplasma antibody titres in the patient and cat were as shown in the Table:

\begin{tabular}{lccccc}
\hline 1978 & 5 January & \multicolumn{2}{c}{ February } & 31 May & 7 August \\
& 7 & 14 & & \\
\hline Patient & & & & & \\
Immunofluorescence & & & & \\
$\quad$ IgM & 128 & 64 & 32 & 32 \\
IgG & 1024 & 1024 & & & \\
Comple- & 128 & 128 & & 500 & 500 \\
$\quad$ ment & & & & & \\
fixation & 1000 & 4000 & & & \\
$\begin{array}{l}\text { Dye test } \\
\text { Cat }\end{array}$ & & 1024 & 250 & & \\
Immunofluorescence & & &
\end{tabular}

As both a significant increase in dye test titre and toxoplasma antibodies of the IgM-class were demonstrable, 